\title{
Antioxidant strategies for preventing oxidative flavour deterioration of foods enriched with n-3 polyunsaturated lipids: a comparative evaluation
}

Jacobsen, Charlotte; Let, M.B.; Nielsen, Nina Skall; Meyer, Anne S.

Published in:

Trends in Food Science \& Technology

Link to article, DOI:

10.1016/j.tifs.2007.08.001

Publication date:

2008

Link back to DTU Orbit

Citation (APA):

Jacobsen, C., Let, M. B., Nielsen, N. S., \& Meyer, A. S. (2008). Antioxidant strategies for preventing oxidative flavour deterioration of foods enriched with n-3 polyunsaturated lipids: a comparative evaluation. Trends in Food Science \& Technology, 19(2), 76-93. https://doi.org/10.1016/j.tifs.2007.08.001

\section{General rights}

Copyright and moral rights for the publications made accessible in the public portal are retained by the authors and/or other copyright owners and it is a condition of accessing publications that users recognise and abide by the legal requirements associated with these rights.

- Users may download and print one copy of any publication from the public portal for the purpose of private study or research.

- You may not further distribute the material or use it for any profit-making activity or commercial gain

- You may freely distribute the URL identifying the publication in the public portal 


\section{Antioxidant strategies for preventing oxidative flavour deterioration of foods enriched with n-3 polyunsaturated lipids: A comparative evaluation}

Charlotte Jacobsen $^{1 *}$, Mette Bruni Let ${ }^{1}$, Nina Skall Nielsen ${ }^{1}$ and Anne S. Meyer ${ }^{2}$

${ }^{1}$ Department of Seafood Research, Danish Institute for Fisheries Research, B.221, DTU, DK-2800

Kgs. Lyngby, Denmark

${ }^{2}$ BioProcess Engineering, Department of Chemical Engineering, Technical University of Denmark, DK-2800, Kgs. Lyngby, Denmark

*corresponding author: cja@difres.dk 


\begin{abstract}
The aim of this review is to provide a better base for predicting the ability of antioxidants to prevent lipid oxidation in food emulsions in general and in functional food systems enriched with n-3 PUFA in particular. Therefore, the antioxidant efficacies of a range of commercially available antioxidants in a number of fish oil enriched real food emulsions (milk, milk drink, salad dressing, mayonnaise and selected model emulsions) are compared. This comparison clearly shows that the same antioxidant exerts different effects in different systems. EDTA is a very efficient antioxidant in salad dressing and mayonnaise, but not in milk, while ascorbyl palmitate efficiently reduces oxidation in milk. Furthermore, the comparative data evaluation confirms that the same antioxidant in some cases may exert opposite effects on peroxide levels and on formation of individual volatiles and fishy odour and flavours. Therefore, antioxidant effects should always be evaluated by more than one method.
\end{abstract}

\title{
Introduction
}

Functional foods containing n-3 lipids is one of the fastest growing food product categories in the US and Europe (Frost \& Sullivan Research Service 2005). A prerequisite for successful development of foods enriched with lipids containing n-3 polyunsaturated fatty acids (PUFA) is that oxidation of the lipids is prevented. Unfortunately, the lipid oxidation and antioxidant mechanisms in multiphase food systems are very complex and many factors can influence the rate and extent of lipid oxidation, and the efficacy of different antioxidants in such systems. Because of this complexity it is currently difficult to predict the behaviour and efficacy of antioxidants in different multi-phase systems. This review will discuss the current knowledge on the efficacy of different antioxidants in n-3 PUFA enriched food systems, with particular focus on protection of food emulsions enriched with fish oils. The aim is to provide a better base for predicting the protective effects of antioxidants and other antioxidative measures in food emulsions in general and in functional food systems enriched with n-3 PUFA in particular. 


\section{Background}

Nutritional effects of $n-3$ polyunsaturated fatty acids: During the last thirty years there has been an increasing interest in n-3 polyunsaturated lipids in relation to food, nutritional and pharmaceutical applications. This is due to the increasing evidence that n-3 PUFA elicit a wide range of nutritional benefits in the human body. From a nutritional point of view, the three most important n-3 PUFA are $\alpha$-linolenic acid (LNA, C18:3 n-3), eicosapentaenoic acid (EPA, C20:5 n-3) and docosahexaenoic acid (DHA, C22:6 n-3). The potential health effects of EPA and DHA include reduction of cardiovascular disease risk ; ; , anti-inflammatory effects including reduction of symptoms of rheumatoid arthritis and Crohns disease, and reduced risk of certain cancer forms . Moreover, DHA seems to be important for brain and nervous tissue development in infants. The evidence for the preventive effect of EPA and DHA on cardiovascular disease is particularly strong . In September 2004 the US Food and Drug Administration allowed the use of a qualified health claim for reduced risk of coronary heart disease on conventional foods that contain EPA and DHA (US Food and Drug Administration ). EPA and DHA occur in marine organisms, notably in fatty fish, while LNA is mainly found in plant based foods. In this review, the main focus will be on the marine n-3 PUFA and for this reason n-3 PUFA only refers to EPA and DHA in the following, and PUFA are to be understood as polyunsaturated fatty acids in their triglyceride structure.

Dietary intake and sources of n-3 PUFA. The current intake of n-3 PUFA in the industrialised world is lower than recommended by nutritional organisations (Kris-Etherton et al. 2000; Sioen et al. 2006). The most obvious way to secure an increased intake of these healthy fatty acids in the population is via increased dietary fish consumption. However, it is apparently difficult to change the dietary habits of the Western populations towards a higher fish intake, probably because many different "attitude factors", and not only putative health benefits, influence fish consumption (Verbeke \& Vackier 2005). Therefore, efforts have been made to substitute part of the vegetable or animal fat by marine lipids in foods like mayonnaise, milk, bread, salad dressing, spreads, yoghurts etc. . 
Oxidation problems: Due to their unsaturated nature n-3 PUFA are more susceptible to lipid oxidation than less unsaturated lipids. Lipid oxidation gives rise to the formation of undesirable offflavours and unhealthy compounds such as free radicals and reactive aldehydes. The off-flavours formed from n-3 PUFA oxidation are particularly unpleasant. Furthermore, the human sensory apparatus has a low threshold for volatile off-flavours resulting from oxidation of n-3 PUFA (Frankel, 2005). Thus, off-flavours developed in n-3 PUFA enriched mayonnaise, milk drink, fish oil powder, egg and bread have been described as rancid, fishy, train oil, metallic, painty or simply as an unspecific off-flavour

\section{Factors affecting lipid oxidation in $\mathrm{O} / \mathrm{W}$ emulsion systems}

Foods are often complex systems comprised of different phases and constituents, e.g. air, water, lipid and solid particles. Oil-in-water (O/W) emulsions such as milk, mayonnaise and salad dressing constitute a particularly large - and widely consumed - group of such complex, heterophasic food systems. In both $\mathrm{O} / \mathrm{W}$ and in water-in-oil (W/O) emulsions, including margarine and butter, the oil and the aqueous phases are separated by an interface comprised of amphiphilic compounds (emulsifiers). Lipid oxidation in emulsions is generally recognized as being very complex as it may include oxidation or electron transfer events in all the different phases of the systems, making the mechanisms of lipid oxidation in emulsions very different and significantly more complex than lipid oxidation in bulk oil systems. Hence, although the basic oxidation reactions of lipids present in emulsions are exactly the same as those of lipids in bulk oils, the factors affecting lipid oxidation in emulsions, and notably the significance of different intrinsic factors such as transition metal ions and $\mathrm{pH}$, differ significantly in emulsions and in bulk oil systems. Only few published data are available on lipid oxidation in n-3 PUFA enriched W/O emulsions as compared to in $\mathrm{O} / \mathrm{W}$ emulsions. Moreover, W/O food emulsions represent a more narrow group of food products. For this reason, the main focus in the following will be on $\mathrm{O} / \mathrm{W}$ emulsions, and notably on n-3 PUFA enriched food emulsions. 
Oxidation mechanisms: Oxidation generally occurs faster in $\mathrm{O} / \mathrm{W}$ emulsions than in bulk oils . N-3 PUFA incorporated into emulsions are particularly labile with respect to oxidation because of the relatively harsh processing conditions required for emulsion fabrication, including exposure to air (oxygen) and in some cases high temperature. Also, due to their highly unsaturated nature, n-3 PUFA are particularly labile with respect to a multitude of interfacial interactions with oxidants, including radicals and metal ions. Even after refining and deodorization most oils will contain trace levels of peroxides. Furthermore, several food ingredients contain trace levels of metal ions. Therefore, metal catalysed decomposition of peroxides is regarded as the most important driving force for lipid oxidation in many food systems including food emulsions. In practice, this hydroperoxide decomposition mainly takes place via metal catalysed, homolytic (unimolecular) cleavage of the oxygen-oxygen bond in the peroxide (LOOH), generating a highly reactive alkoxyl lipid radical $\left(\mathrm{LO}^{\circ}\right)$ and a hydroxyl ion $\left(\mathrm{OH}^{-}\right)$:

$\mathrm{LOOH}+\mathrm{Me}^{\mathrm{n}+} \rightarrow \mathrm{LO}^{\bullet}+\mathrm{OH}^{-}+\mathrm{Me}^{(\mathrm{n}+1)^{+}}$

The alkoxyl lipid radicals, $\mathrm{LO}^{\bullet}$, may initiate new reactions, but usually degrade rapidly by carboncarbon cleavage on either side of the radical, to form different volatile decomposition products (offflavors) (Frankel, 2005). Hence, the metal catalysed decomposition of lipid peroxides not only generates free radicals, which initiate further oxidation reactions, but also leads to the formation of secondary volatile oxidation compounds.

The multiphase system: In $\mathrm{O} / \mathrm{W}$ emulsions, the oil droplets are surrounded by an interface and they are not as such in direct contact with air and/or water. Lipid oxidation has frequently been described as an interfacial phenomenon mainly taking place - or mainly being initiated - exactly at the interface where different non-polar and polar compounds in the system can interact. In bulk oils, the oxidation reactions are mainly taking place at the interface between the oil and the air in the headspace above the oil or at the interface between the oil and air dissolved in the oil. The 
phenomenon that the overall oxidation rate is generally faster in emulsions than in bulk oil may thus be attributable to the large interfacial area in emulsions compared with the relatively small interface between air and oil in bulk oils. The total interfacial area in any emulsion obviously depends on the size distribution of the oil droplets, but contradicting reports are available on the effect of the droplet size on oxidation in different food systems ; Let, Jacobsen \& Meyer, 2006a). The available data thus suggest that other factors than the mere interfacial area are of significance for oxidation. Such other factors may include the thickness and charge of the interfacial boundary, and the metal binding capacity of the emulsifier. In $\mathrm{O} / \mathrm{W}$ emulsions, prooxidant concentrations are often highest in the aqueous phase, and therefore oxidation may be initiated in the aqueous phase or at the interface rather than in the oil phase "inside" the oil droplets. Oxygen, prooxidant metals, and water soluble antioxidants must therefore diffuse through the aqueous phase before reaching the oil droplets or the $\mathrm{O} / \mathrm{W}$ interface. For this reason differences in solubility properties, mobility and mass transfer rates of transition metals and antioxidants through different phases may affect oxidation significantly in emulsions. An important property of oxygen is that it is more soluble in oil than in water $([\mathrm{O} 2$ oil $]=$ ca. $1.2 \mathrm{mM} \quad[\mathrm{O} 2 \mathrm{aq}]=\mathrm{ca} 0.25 \mathrm{mM})($ Battino, 1987; Weast, Astle and Beyer, 1987) and this may also influence oxidation rates. Unfortunately, many crucial details about mass transfer rates and partitioning of antioxidants in genuine food emulsions are still largely unknown.

The significance of the emulsifier and $p H$ : Food emulsions require addition of an emulsifier for physical stability. Basically, emulsifiers are surface active molecules with amphiphilic properties, which can interact with oil and water interface and reduce surface tension. However, many emulsifiers are able to interact with other components of the food product, and the choice of emulsifier can therefore be of significant importance for both physical and oxidative stability of the food product. Emulsifiers for food use can be either macromolecules, such as proteins unfolding at the interface, or smaller surfactant molecules, such as phospholipids, free fatty acids, di- and monoacylglycerols and synthetic surfactants. Emulsifiers are able to affect lipid oxidation in different ways. One way is by influencing the thickness of the interface. Moreover, in emulsions 
stabilised by proteins, $\mathrm{pH}$ will generally be either below or above the $\mathrm{pI}$ of the protein in order to avoid coalescence of droplets. Hence, the emulsified droplets may have either a positive or negative surface charge. The surface charge of emulsion droplets is important for lipid oxidation catalysed by trace metal ions, such as $\mathrm{Fe}^{2+}$. With a negative surface charge, emulsion droplets will attract the potentially highly prooxidative positively charged trace metals, and bring them into closer proximity of the n-3 PUFA oil, thereby enhancing lipid oxidation . If instead an emulsifier which creates a positive charge of the droplets is chosen, trace metals - notably $\mathrm{Fe}^{2+}$ and $\mathrm{Fe}^{3+}$ - may be repelled and oxidation is likely to be reduced. Another aspect is the fact that the solubility of trace metals generally increases at decreasing $\mathrm{pH}$. The increased trace metal solubility then potentially promotes oxidation. Since different emulsifiers are used in different food emulsions, and $\mathrm{pH}$ values also vary in different types of food emulsions, the significance of the emulsifier and the $\mathrm{pH}$ varies in different systems. In turn, this means that different oxidation mechanisms prevail in different emulsion systems.

\section{Antioxidants in food emulsions}

Antioxidant efficacy in multiphase systems depends on many factors, but particularly the partitioning of the antioxidant into the different phases seems to be an important factor. The socalled polar paradox of antioxidant efficiency in emulsions and bulk oils, proposed by appears to be a direct result of antioxidant partitioning. According to the polar paradox, polar antioxidants like ascorbic acid and Trolox are more active in non-polar media like bulk oils than their more non-polar counterparts ascorbyl palmitate and tocopherol. These apparent paradoxical effects of the antioxidants have been suggested to be a result of the polar antioxidants being located at the air-oil interface in bulk oils, i.e. situated where oxidation is suggested to take place - or at least to be initiated. On the other hand, lipophilic antioxidants such as tocopherols and ascorbyl palmitate are more active in polar systems like $\mathrm{O} / \mathrm{W}$ emulsions, because the nonpolar, lipid soluble antioxidants will be located in the oil phase where oxidation propagates. However, other factors than antioxidant partitioning affect antioxidant efficacy in heterophasic systems like $\mathrm{O} / \mathrm{W}$ emulsions and, 
as mentioned previously, different oxidation mechanisms therefore prevail in different food emulsions. Because of this variable dominance of different mechanisms of oxidation in different emulsion systems, the efficacy of different antioxidants - and antioxidant mechanisms (e.g. oxygen scavenging, metal chelation, chain breaking), - varies significantly in different types of emulsions. Provision of an improved understanding of antioxidant partitioning as well as of the different oxidation mechanisms and dynamics in complex emulsion systems thus seem to be a prerequisite for predicting antioxidant efficacy in real n-3 PUFA enriched food emulsions.

\section{Comparison of antioxidant effects}

This review is based on available literature reports concerning evaluation of antioxidants in food emulsions enriched with n-3 PUFA. Since the number of studies in real food emulsions is limited we have also included selected results obtained in simple $\mathrm{O} / \mathrm{W}$ model emulsions. Moreover, a few data obtained with modified PUFA made from plant oils have been included, because they have been obtained in the same food matrices as the data concerning n-3 PUFA. The comparison has been limited to selected commercially available antioxidants with the exception of gallic acid, which has often been included as the polar counterpart to propyl gallate (PG). To quantify the effect of antioxidants the maximum \% inhibition obtained during storage has been calculated using the following formula:

$$
\% \text { inhibition }=[(\text { control }- \text { antioxidant sample }) / \text { control }] \cdot 100 \% \text {, }
$$

The control represents the measured value of extent of oxidation (eg peroxide value (PV) or concentration of a volatile compound) of the control sample without antioxidant, and antioxidant sample represents the analogous extent of oxidation measured for the sample containing antioxidant. In the following, antioxidant effects have been graduated according to extent of inhibition as outlined in Table 1. 
The maximum \% inhibition has been calculated for PV, concentration of selected volatiles and intensity of fishy odour and flavour. In a few cases, thiobarbituric acid reactive substances (TBARS) have been used instead of concentration of volatiles because data on volatiles were not available. It has not been possible to make statistical analysis on this comparison of \% inhibition from different studies. However, when interpreting the data obtained from the calculations in the present paper, the conclusions made in the original manuscripts were also carefully taken into account. These conclusions were generally based on statistical analysis of the original data. The composition and storage details for the emulsions are shown in Table 2.

\section{Legislation and selected antioxidants}

The legislation in the US and in the EU for the application of the antioxidants in the foodstuffs mentioned in Tables 3 to 7 is as follows: Ascorbic acid, ascorbyl palmitate and tocopherols are permitted in beverages based on milk and in salad dressings and mayonnaise in both the US and in the EU (FDA 2006; Foedevarestyrelsen 2005). Propyl gallate and gallic acid are also permitted in these products in the US, but only permitted in salad dressings and mayonnaise in the EU. EDTA (ethylenediamine tetraacetic acid) is only permitted in dressings and mayonnaise both in the US and the EU and not in beverages produced from milk. Lactoferrin has not yet been approved for application as antioxidant in any of these regions.

\section{Effect of EDTA}

When addition of the metal chelator EDTA has been evaluated as an antioxidative measure in food emulsions, the addition level of EDTA has usually been from 4 to $240 \mathrm{mg} / \mathrm{kg}$ product with concentrations in the range of 5 to $50 \mathrm{mg} / \mathrm{kg}$ product being the most frequently used (Table 3 ). From the available data it can be concluded that EDTA's efficacy varies significantly in different emulsion systems, and decreases in the order mayonnaise $\approx$ salad dressing $>$ model emulsions $>$ milk drink with strawberry flavour and $5 \%$ fat $>$ milk with $1.5 \%$ fat (Table 3 ). In the following the strawberry flavoured milk drink containing $5 \%$ fat will be termed milk drink. 
Primary and secondary oxidation products: Addition of EDTA has been found to inhibit peroxide formation by more than $75 \%$ in mayonnaise, salad dressing and in certain model emulsions (Table 3). In model emulsions with lecithin-chitosan addition of EDTA has proven to be less efficient in inhibiting oxidation, albeit still exhibiting pronounced effects to retard lipid oxidation (Table 3). EDTA has also been found to inhibit formation of volatiles and TBARS in lecithin-chitosan model emulsions with 5\% oil, but again the antioxidative efficiency was lower in this system than in other model emulsions. In salad dressing and mayonnaise, EDTA seems to prevent formation of heptadienal better than it inhibits hexanal formation (Table 3). The higher efficacy of EDTA against formation of heptadienal as compared to formation of hexanal has also been observed in milk with $1.5 \%$ fat when $100 \%$ of this fat was from cod liver oil (Table 3). In contrast, EDTA apparently does not effectively inhibit peroxide formation in milk containing $1.5 \%$ fat. In the studies conducted so far, EDTA's effect on volatiles formation in fish oil enriched milk appears to depend on the fish oil used and on the concentration of fish oil (Table 3). Hence, EDTA seems to be more efficient when a high concentration of fish oil (1.5\% vs $0.5 \%)$ or fish oil with a high PV (1.48 $\mathrm{meq} / \mathrm{kg}$ vs $<0.2 \mathrm{meq} / \mathrm{kg}$ ) is used, but the mechanisms underlying these different effects of EDTA may be related to other factors in the systems. In a milk drink system with $5 \%$ fat EDTA's efficacy against peroxide formation has been found to be higher than its effect in milk with $1.5 \%$ fat, even though the overall efficiency of EDTA in these milk based beverages appears to be lower than in mayonnaise. In the milk drink, the hexanal data indicate that EDTA apparently is more efficient when a modified vegetable oil (SSO) with a high content of n-6 PUFA has been used compared to when modified fish oil (SFO) is applied. Interestingly, EDTA was found to promote the formation of saturated aldehydes in the SFO milk drink, while its effect on unsaturated aldehydes and alcohols was more unclear (Timm-Heinrich, Xu, Nielsen \& Jacobsen, 2004).

Fishy odour and flavour: The sensory data clearly shows that EDTA is a very efficient antioxidant preventing off-flavours in mayonnaise and a less efficient antioxidant in milk with $1.5 \%$ fat (Table 3). It is worth noting, however, that the data for the milk drink with $5 \%$ fat and $0.5 \%$ structured 
fish oil shows that EDTA can effectively reduce off-flavour formation in this milk system irrespective of its less pronounced effect on PV and hexanal formation (Table 3).

Discussion of EDTA's effects: Since EDTA is a metal chelator, the higher efficacy of EDTA in mayonnaise and salad dressing as compared to in milk systems indicates that metal catalysed oxidation plays a larger role in mayonnaise and salad dressing than in the examined dairy emulsions. Mayonnaise and salad dressing are both acidified, high fat emulsion systems. Furthermore, the emulsifier in the mayonnaise studied was based on egg yolk, while it was based on whey protein in the salad dressing system. It has previously been proposed that iron from egg yolk combined with the low $\mathrm{pH}$ are the most important factors to oxidation in mayonnaise, and the data compiled here strongly support this conclusion. In the particular mayonnaise system referred to in the present review, the content of iron in the egg yolk emulsifier was approximately $730 \mu \mathrm{M}$, whereas the content of iron in the whey protein used as an emulsifier in the salad dressing system has not been published. However, from the available knowledge on whey protein emulsifiers, the iron content must be expected to be relatively low, that is much lower than in egg yolk. For this reason it seems surprising that metal catalysed oxidation is so prominent in a whey protein emulsified salad dressing. One explanation may be that a low $\mathrm{pH}$ in combination with even small levels of protein bound metal ions can intensify metal catalysed oxidation in food emulsions. This hypothesis is further supported by the finding that EDTA seemed to be able to prevent oxidation in the model emulsions to a greater extent when whey protein was used as an emulsifier compared to when lecithin/chitosan was used as the emulsifying agent. The apparent lower importance of metal catalysed oxidation in milk emulsions (derived from the weak effect of EDTA in these emulsions) could be due to the higher $\mathrm{pH}, \mathrm{pH} \sim 6.5$, and to a different physical structure, protein composition, and notably a lower iron content at the $\mathrm{O} / \mathrm{W}$ interface in these systems. The milk with $1.5 \%$ fat contained approximately $175 \mathrm{ng} / \mathrm{g}$ iron and $48 \mathrm{ng} / \mathrm{g}$ copper, while the mayonnaise, with $80 \%$ fat, contained approximately $1700 \mathrm{ng} / \mathrm{g}$ iron and almost no copper. These data support the putative positive correlation between antioxidative EDTA efficacy and level of metal ions in the system. 
The particular results showing that the efficacy of EDTA in milk with $1.5 \%$ fat depended on the fish oil used and its concentration (Table 3) were most likely related to the fact that oxidation is less pronounced when a high quality fish oil is used. With respect to volatiles, the different effects of EDTA on heptadienal and hexanal observed in mayonnaise and milk are most likely due to the different origin of these volatiles rather than to the different metal ion levels in the systems. Heptadienal is formed from peroxides originating from n-3 fatty acids ( $n-3$ peroxides), whereas hexanal stems from n-6 fatty acids (n-6 peroxides). N-3 peroxides are more polar than n- 6 peroxides. Therefore, n-3 peroxides may to a higher degree partition into the aqueous phase or the $\mathrm{O} / \mathrm{W}$ interface than $\mathrm{n}-6$ peroxides. EDTA is a polar compound that will primarily, if not completely, be located in the aqueous phase in emulsion systems. Hence, the co-localisation of EDTA and n-3 peroxides in the aqueous phase may make EDTA more efficient in preventing decomposition of n-3 peroxides as compared to $n-6$ peroxides. In addition, peroxides stemming from EPA and DHA are particularly sensitive to metal catalyzed degradation due to their high number of double bonds (Frankel, 2005); for this reason EDTA will have a relatively larger significance on retarding volatiles formation from n-3 PUFA peroxides than from n-6 peroxides.

EDTA has also been evaluated in other n-3 PUFA enriched food products than those shown in Table 3. Thus, in fish oil enriched salmon paté addition of EDTA or citric acid slightly promoted formation of volatile oxidation products, but at the same time EDTA exerted a small positive impact on the sensory perception of the samples, while citric acid did not (Olsen et al., 2006).

\section{Effect of lactoferrin}

Lactoferrin is a milk glycoprotein occurring naturally in numerous bodily secretions, including milk, tears, mucus, blood, and saliva. Lactoferrin is also the main iron-bearing protein in cow's milk, and it is able to bind two $\mathrm{Fe}^{3+}$ in cooperation with two $\mathrm{HCO}^{3-}$ ions when fully saturated. Previous studies have shown that lactoferrin is able to reduce lipid oxidation in infant formula (Satue-Gracia et al., 2000) and in certain iron catalyzed corn oil emulsions (Huang et al., 1999). The inhibitory action of lactoferrin is supposed to take place by metal chelation, notably of iron. 
Antioxidative protection of n-3 PUFA enriched systems by lactoferrin has only been evaluated in a few fish oil enriched systems: milk drink and mayonnaise. The lactoferrin concentrations tested have ranged from 500 to $2826 \mathrm{mg} / \mathrm{kg}$ (Table 4). The high addition levels are due to the high molecular weight $(\sim 80.000 \mathrm{~g} / \mathrm{mole})$ of lactoferrin. Although the current data are too scarce to allow overall conclusions to be drawn, a few trends can be discerned: lactoferrin appears to exhibit a concentration dependent protective effect in both mayonnaise and milk drink systems, but even at its optimum addition levels, which are not necessarily at the highest levels of addition (Table 4), lactoferrin only exerts a weak antioxidant effect against oxidation of n-3 PUFA in emulsions.

Effect on primary and secondary oxidation products and sensory properties: In mayonnaise, the optimum antioxidative effect on peroxides (60\% inhibition) has been found to be at the lowest lactoferrin addition level (Table 4), while no clear effect of lactoferrin on hexanal has been observed. In a milk drink with SSO, prooxidative or weak antioxidative effects have been observed for both peroxides and hexanal with the highest inhibition of hexanal formation being obtained with $1000 \mathrm{mg} / \mathrm{kg}$ lactoferrin (Table 4). A concentration of $1000 \mathrm{mg} / \mathrm{kg}$ lactoferrin has also been found to provide the highest level of inhibition of other volatiles, but even at this optimum concentration, the inhibitory effect was found to vary between -73 to $76 \%$ with most values between 0 and $25 \%$ inhibition (10 out of 13 volatiles). Hence, a general conclusion on the antioxidative effect of lactoferrin on milk drink with high levels of n-6 PUFA cannot be drawn from the available data. For the milk drink system with SFO an intermediate antioxidative effect on peroxides and a relatively weak effect on formation of hexanal and most other volatiles have been observed . Nevertheless, it has been found that lactoferrin prevents formation of fishy odour and flavour in milk drink with SFO (Table 4). However, from the available data it cannot be concluded whether the $\%$ fishy flavour reduction would be satisfactory from a consumer point of view.

Discussion of the effect of lactoferrin: Lactoferrin is a metal chelator like EDTA, but it has a lower binding constant towards $\mathrm{Fe}^{3+}$ than EDTA $\left(10^{20}\right.$ vs $\left.1.3 \times 10^{25} \mathrm{M}^{-1}\right)$ (Masson and Heremans, 1968; Skoog and West, 1976) and this difference may explain the higher efficacy of EDTA compared to 
lactoferrin in mayonnaise (compare Table 3 vs Table 4). Another factor could be that lactoferrin in contrast to EDTA may be more sensitive to $\mathrm{pH}$ values around 4. Lactoferrin is able to bind metals at two sites. The reason why lactoferrin sometimes exerts prooxidative effects has been speculated to be a result of a cascade of events taking place at the oil-water interface: hence, if lactoferrin is located near the $\mathrm{O} / \mathrm{W}$ interface and thereby comes in close contact with the lipid droplet in the emulsions, lactoferrin might change conformation and bind metal ions at sites other than its metal chelating sites. Such binding could result in prooxidant effects by bringing the metal ions in contact with the lipid Effect of tocopherols

Tocopherols have been evaluated in mayonnaise, salad dressing, milk with $1.5 \%$ fat, and simple model emulsions (Table 5). In mayonnaise, mixtures of tocopherol homologs as well as a combination of $\gamma$-tocopherol, lecithin and ascorbic acid (the A/L/T-system) have been evaluated. In salad dressing, only $\gamma$-tocopherol has been evaluated, but in milk with $1.5 \%$ fat and in model emulsions, both addition of mixtures of tocopherol homologs and single tocopherol compounds have been evaluated. Addition levels have ranged widely from 0.8 to $500 \mathrm{mg} / \mathrm{kg}$ product. Taken together, the available data show that tocopherols do not exert efficient antioxidant effects in real food emulsions enriched with n-3 lipids (Table 5). However, both $\alpha$ - and $\delta$-tocopherol efficiently prevented oxidation in a model emulsion with Brij as emulsifier (Chaiyasit, McClements, \& Decker, 2005).

Effect on primary and secondary oxidation products: In mayonnaise, the effects of tocopherols have been found to be concentration dependent and also to depend on whether a water or an oil soluble tocopherol mixture (both from Danisco Ingredients, Aarhus, Denmark) is used (Table 5). With an oil soluble tocopherol mixture prooxidative effects on peroxide formation have been observed at low concentrations while the highest addition level of the oil soluble preparation $(112 \mathrm{mg} / \mathrm{kg})$ exhibited a clear inhibitory effect on PV development (Table 5). In contrast, antioxidative effects on volatiles have only been seen at lower tocopherol concentrations, with the highest protection observed with the lowest concentration $(16 \mathrm{mg} / \mathrm{kg})($ Table 5). Addition of a tocopherol mixture as a 
water soluble preparation in mayonnaise, resulted in the highest protection against both peroxides and volatiles formation with the lowest tocopherol concentration $(16 \mathrm{mg} / \mathrm{kg})$ (Table 5).

Interestingly, the $\mathrm{A} / \mathrm{L} / \mathrm{T}$ system appears to provide a relatively good protection against peroxide formation in mayonnaise, but clearly promotes the formation of volatiles. In salad dressing, $\gamma$ tocopherol has been found to exert an intermediate inhibitory effect on peroxide formation irrespective of the addition level. In contrast, an inverse concentration dependent effect has been observed for the volatiles, where the highest protection has been obtained with the lowest concentration (22 $\mathrm{mg} / \mathrm{kg}$ product). In milk, addition of a combination of $\alpha$ - and $\gamma$-tocopherol does not appear to have any effect on peroxides, but a prooxidative effect on volatile formation (Table 5). The addition of pure $\alpha$-tocopherol in a concentration of $1.1 \mathrm{mg} / \mathrm{kg}$ or $\gamma$-tocopherol in concentrations of 0.8 or $3.3 \mathrm{mg} / \mathrm{kg}$ have been found to only result in weak antioxidative effects on the formation of volatiles in milk. Meanwhile, a much better effect has been observed with a $\gamma$-tocopherol alone in a concentration of $1.7 \mathrm{mg} / \mathrm{kg}$ (Table 5) For the model emulsions, the best protection on both peroxides and volatiles has been found in emulsions made with Brij, where up to $96 \%$ inhibition by $\alpha$ - or $\delta$ - tocopherol has been seen. In contrast, mixtures of tocopherols clearly exert prooxidative effects on peroxides in emulsions made with lecithin and chitosan (Table 5).

Effect on sensory properties: In mayonnaise, addition of an oil soluble tocopherol mixture has been found to exhibit prooxidative effects on both fishy odour and flavour at high concentrations $(>32$ $\mathrm{mg} / \mathrm{kg}$ ) and low to intermediate antioxidative effects at lower concentrations (Table 5). A water soluble tocopherol mixture has similar effects on odour, but has been found to generally exert prooxidative effects on fishy flavour. For both oil and water soluble tocopherol mixtures prooxidative effects on fishy odour and flavour have also been found at other time points during storage than those shown in Table 5, even when the lowest concentrations were used. These observations suggest that tocopherols do not have any distinct effects on fishy odour and flavour in mayonnaise. However, when tocopherol is added as the $\mathrm{A} / \mathrm{L} / \mathrm{T}$ system it strongly promotes the formation of fishy odour and flavour. In milk, a mixture of $\alpha$ - and $\gamma$-tocopherol has been found to 
promote fishy odour and flavour (Table 5). Recent, preliminary results have, however, indicated that addition of $1.7 \mathrm{mg} / \mathrm{kg} \gamma$-tocopherol to $\mathrm{n}$-3 PUFA enriched milk can result in some protection against fishy taste development (unpublished results).

Discussion of the effects of tocopherols: The poor effect of tocopherol observed in food emulsions may be a result of the high levels of tocopherols already present in the oils used in these products. In particular, the fish oil used for the milk systems examined here contained high concentrations of $\alpha$-tocopherol (Table 3). It is well known that $\alpha$-tocopherol can have prooxidative effects in high concentrations . Hence, the milk data suggests that this prooxidative effect already occurs at a total $\alpha$-tocopherol level of ca. $2.7 \mathrm{mg} / \mathrm{kg}$ milk. Interestingly, the range within which $\gamma$-tocopherol has its optimal concentration is narrow as the optimal concentration is $1.7 \mathrm{mg} / \mathrm{kg}$, while both 0.8 and 3.3 $\mathrm{mg} / \mathrm{kg}$ give poorer results. The narrow concentration range for an optimal effect is also seen for development of other volatiles than those showed in Table 5 . Comparison of the results obtained with $32 \mathrm{mg} / \mathrm{kg}$ water soluble tocopherol mixture in mayonnaise from different experiments shows quite different $\%$ inhibition for both the chemical data and for the sensory data. This discrepancy may partly be due to the slightly different tocopherol levels present in the oils used for the mayonnaises, which leads to different total concentrations of tocopherol (Table 5). Moreover, when $\%$ inhibition was calculated on the sensory data both pro- and antioxidative effects of this tocopherol concentration were observed during storage. The antioxidative effect was not always obtained at the same time point. This problem makes comparison of the sensory data obtained in different studies with tocopherols difficult. Since tocopherols have only been evaluated as mixtures in mayonnaise, it cannot be ruled out that better effects may be exerted by $\gamma$-tocopherol (or by other tocopherol homologues) alone. In contrast to milk, mayonnaise also contains rapeseed oil (64 \%), which has a very high level of $\gamma$-tocopherol, so the question is whether additional $\gamma$-tocopherol will have any effect in mayonnaise. Moreover, suggested that the crucial step in the formation of fishy odour and flavour in mayonnaise is the metal catalysed break down of peroxides from n-3 PUFA located in the aqueous phase or at the $\mathrm{O} / \mathrm{W}$ interface. If this is the case, tocopherol can only to a 
limited extent reduce off-flavour formation by inhibiting deterioration of n-3 PUFA inside the oil droplets, because the reactions between the n-3 PUFA and the radicals formed from the decomposing peroxides will take place at the $\mathrm{O} / \mathrm{W}$ interface. The strong prooxidative effects of the $\mathrm{A} / \mathrm{L} / \mathrm{T}$ system in mayonnaise are presumably due to ascorbic acid, and the mechanism behind this presumed prooxidative effect of ascorbic acid will be dealt with below. The finding that tocopherol is a much better antioxidant in the Brij model emulsion as compared to in the genuine food emulsions may be due to the less complex nature of the model emulsion(s) and to the fact that oxidation of the model emulsions was catalysed by heat $\left(37^{\circ} \mathrm{C}\right)$ and not by the addition of metal ions . Under these circumstances, the ability of tocopherol to scavenge free radicals may be enough to inhibit lipid oxidation, while this is not the case in the more complex food emulsions in which several different oxidation mechanisms may prevail.

\section{Effects of ascorbic acid and ascorbyl palmitate}

Ascorbic acid has only been evaluated in mayonnaise, while ascorbyl palmitate (AP) has been evaluated in both mayonnaise, salad dressing, milk with $1.5 \%$ fat and milk drink (Table 6). Ascorbic acid has been evaluated in a wide range of concentrations from 40 to $4000 \mathrm{mg} / \mathrm{kg}$, while AP has been evaluated in concentrations ranging from 1.5 to $30 \mathrm{mg} / \mathrm{kg}$. The data clearly show that ascorbic acid and AP are strong prooxidants in mayonnaise (at concentrations $\geq 40 \mathrm{mg} / \mathrm{kg}$ ). In the salad dressing and milk drink AP exhibits a concentration dependent effect being prooxidative at the highest addition levels of $30 \mathrm{mg} / \mathrm{kg}$ and at $\geq 7.5 \mathrm{mg} / \mathrm{kg}$ in salad dressing and milk drink, respectively. Interestingly, AP works better as an antioxidant in milk with $1.5 \%$ fat than in any of the other tested food systems (Table 6).

Effect on primary and secondary oxidation products: In mayonnaise, both ascorbic acid and AP have strong inhibitory effects on PV development with up to $100 \%$ inhibition at high concentrations of ascorbic acid (2000 and $4000 \mathrm{mg} / \mathrm{kg}$ ) (Table 6). In contrast, AP and especially ascorbic acid, exhibit strong prooxidative effects on formation of volatiles, notably on $t$-2-hexenal 
formation (Table 6). Despite of this AP has been found to inhibit the formation of hexenal by $57 \%$ when added to the oil phase and ascorbic acid inhibits heptadienal formation when added in high concentrations (2000 and $4000 \mathrm{mg} / \mathrm{kg}$ ) to the aqueous phase (Table 6). In salad dressing, an inverse concentration dependent effect on both peroxides and volatiles has been observed with higher protection at the lowest concentration $(5 \mathrm{mg} / \mathrm{kg})$ - but since only two dosage levels were tested, these results have to be interpreted with caution, especially since the inhibitory effects at the lowest concentration are only intermediate in antioxidant potency (Table 6). In milk with $1.5 \%$ fat, AP exerts a strong antioxidative effect at an addition level of only $1.5 \mathrm{mg} / \mathrm{kg}$. In the milk drink with fat levels of $5 \%$, however, the effects appear more complex: for peroxides the highest protection has been observed at high AP concentrations of 15 or $30 \mathrm{mg} / \mathrm{kg}$, but mainly on PV development (Table 6). However, AP has consistently been found to be able to reduce the formation of heptadienal, irrespective of the amount added. In contrast, AP promotes the formation of hexenal and nonadienal when added in concentrations of $7.5 \mathrm{mg} / \mathrm{kg}$ and higher, but reduces the formation of these two volatiles when added at a lower concentration of $3.75 \mathrm{mg} / \mathrm{kg}$. However, in the milk drink, the antioxidative effect of this AP concentration is much lower than in milk with $1.5 \%$ fat (approx 20 $\%$ vs $90 \%)$.

Effect on sensory properties: In mayonnaise, both ascorbic acid and AP have been found to significantly promote the formation of fishy odour and flavour with ascorbic acid having the strongest effect on especially fishy flavour (Table 6). In milk with $1.5 \%$ fat, AP addition has been found to efficiently reduce fishy odour and flavour by approximately $70 \%$. In the milk drink supplemented with $2.5 \%$ structured fish oil, addition of 15 or $30 \mathrm{mg} / \mathrm{kg}$ AP apparently promotes the formation of fishy odour and flavour. This prooxidative effect seems to be largest at the highest AP concentration. Unfortunately, the effect of lower concentrations of AP on the sensory properties has not been evaluated.

Discussion of AP and ascorbic acid effects: The strong prooxidative effect of ascorbic acid in mayonnaise has been suggested to be due to the ability of ascorbic acid to release the phosvitin- 
bound iron from egg yolk in mayonnaise and to reduce it to the active $\mathrm{Fe}^{2+}$ form . The $\mathrm{Fe}^{2+}$ subsequently induces oxidation by decomposing peroxides. AP most likely has the same effect. Similar prooxidative effects of ascorbic acid have been reported in an $\mathrm{O} / \mathrm{W}$ emulsion with $5 \%$ algae oil and with whey protein as an emulsifier . The prooxidative effect was more pronounced at $\mathrm{pH} 3$ than at $\mathrm{pH}$ 7. The prooxidative effect of ascorbic acid was ascribed to its ability to reduce transition metals to increase their prooxidative activity. The increased prooxidative activity at $\mathrm{pH} 3$ was suggested to be due to the fact that iron is more soluble at acidic $\mathrm{pH}$ meaning that more iron could be available to interact with ascorbic acid . The apparent, strong inhibitory effect on PV, observed for AP and ascorbic acid in mayonnaise, salad dressing and strawberry flavoured milk drink is therefore most likely due to the ability of these "antioxidants" to promote the decomposition of peroxides, rather than due to their ability to really inhibit the formation of peroxides. The much stronger antioxidative effects of AP in milk with $1.5 \%$ fat compared to its effect in the milk drink may be due to the different AP concentrations applied. If this is the case, it is possible that AP may also have a stronger antioxidative effect in milk drink if lower concentrations than $3.75 \mathrm{mg} / \mathrm{kg}$ are applied. However, it is also possible that the different compositions of the two milk systems influence the efficacy of AP. Milk with $1.5 \%$ fat does not contain any additives, whereas the milk drink contains mono- and diglycerides, carageenan and guar gum, which may interact at the $\mathrm{O} / \mathrm{W}$ interface and in turn reduce AP's ability to regenerate tocopherol. As AP seems to work best at very low concentrations in salad dressing and in the two milk emulsions examined here, it cannot be ruled out that both AP and ascorbic acid will work better in mayonnaise in lower concentrations than those evaluated. The efficacy of AP seems to depend at least partly on a competition between different antioxidative and prooxidative mechanisms, namely AP's ability to regenerate tocopherol (Marinova and Yanishlieva 1992) and its ability to reduce $\mathrm{Fe}^{3+}$ to $\mathrm{Fe}^{2+}$ and subsequently promote peroxide decomposition and further free radical reactions. The results indicate that if AP concentrations are too high, its iron reducing activity is dominating. The finding that AP works best at low concentrations is in contrast to previous findings that have shown that ascorbic acid is a 
prooxidant in traditional milk in low concentrations and an antioxidant in higher concentrations (Frankel, 2005). It should also be mentioned that the combined effects of tocopherols, ascorbyl palmitate and lecithin have been studied in neat fish oil (Hamilton et al., 1998). Binary systems of ascorbyl palmitate-lecithin and lecithin-gamma/delta or -delta-tocopherol were strongly synergistic in delaying oxidation. The ternary blends provided the greatest protection against autoxidation. Refined fish oil with $2 \% \delta$-tocopherol, $0.1 \%$ ascorbyl palmitate, and $0.5 \%$ lecithin showed no significant oxidation at $20^{\circ} \mathrm{C}$ over a period of 6 months, when evaluated by chemical analysis. However, the antioxidant blend did not prevent oxidation flavour deterioration to the same extent. (Hamilton et al., 1998). The complex effects of ascorbic acid and ascorbyl palmitate alone or in combination with tocopherol deserve further investigation.

\section{Effect of propyl gallate and gallic acid}

PG addition has been evaluated in mayonnaise and gallic acid addition has been studied in mayonnaise and in the strawberry flavoured milk drink (Table 7). The data show that PG and gallic acid exert prooxidative effects in mayonnaise, while gallic acid has been found not to exert any distinct effects on oxidation in the milk drink system.

Primary and secondary oxidation products: For mayonnaise, the PV data show that both PG and gallic acid have prooxidative effects (Table 7). Moreover, PG seems to promote formation of heptadienal and hexenal and has almost no effect on hexanal formation (Table 7). The volatiles data suggest that the prooxidative effect of PG is largest when it is added to the oil phase. Gallic acid has been found to promote the formation of hexanal, but to reduce the formation of heptadienal. In the milk drink gallic acid has been found to have an intermediate to strong inhibiting effect on PV and hexanal (Table 7). According to some of our previous studies, gallic acid also reduces the formation of other volatiles in strawberry flavoured milk drink indicating that gallic acid has a general inhibitory effect on formation of volatiles. 
Effect on sensory properties: Both gallic acid and PG appear to promote the formation of fishy odour and flavours in mayonnaise, albeit a weak antioxidant effect of PG has been observed for fishy flavour in mayonnaise. In the milk drink the available data do not reveal any clear effects of gallic acid.

Discussion of effect of PG and gallic acid: Prooxidative effects of PG and gallic acid have previously been suggested to be due to their ability to reduce metal ions to their more active form, in the case of iron it is the $\mathrm{Fe}^{2+}$ form . A prooxidative effect of gallic acid has also been reported in $\mathrm{O} / \mathrm{W}$ emulsions with whey protein as an emulsifier and $10 \%$ structured lipid based on canola oil The prooxidative effect was more pronounced at $\mathrm{pH} 3$ than at $\mathrm{pH}$. The finding that both $\mathrm{PG}$ and gallic acid show significant prooxidative effects in mayonnaise, but not in milk drink seem to agree with the previous proposition that metal catalyzed oxidation is more important in mayonnaise than in the milk drink. Thus, the consequences of the reduction of metal ions to their active form by the gallates will be greater in mayonnaise than in milk drink. However, it is also possible that the physical structure and composition of the oil-water interface in the milk drink does not allow the gallates to physically access protein bound metal ions and that this can explain the lacking prooxidative effect in this product.

reported that in mayonnaise gallic acid promoted the formation of several alcohols, alkanals, alkenals and alkenones, but that it could also reduce the formation of especially hydrocarbons and alkadienals as also indicated by its inhibiting effect on heptadienal. Hence, the interpretation of whether gallic acid promotes or inhibits oxidation in mayonnaise apparently depends on the type of volatile, which indicates that gallic acid acts differently towards different peroxyl and alkoxyl radicals. As previously mentioned the localisation of peroxides depends of their molecular structure, which in turn is dependent on their origin (e.g. n-3 PUFA vs n-6 PUFA). The different effects of gallic acid on different volatiles may therefore be ascribed to the different locations of the peroxides in heterophasic systems. 


\section{Effect of other antioxidative compounds such as plant extracts}

During the last decade, substantial attention has been given to the possible antioxidative effect of plant extracts and other natural compounds. Nonetheless, there are no data available on the antioxidative effect of these compounds in the fish oil enriched food emulsions considered in the present review. However, a few studies have been carried out in simple $\mathrm{O} / \mathrm{W}$ emulsions. Frankel et al. (1996) observed that the rosemary compounds, carnosol and carnosic acid, were able to inhibit the formation of peroxides and pentenal, but not that of propanal in a $10 \%$ fish oil-in-water emulsion. Interestingly, these compounds were either inactive or prooxidative in $\mathrm{O} / \mathrm{W}$ emulsions prepared with corn oil, soya oil or peanut oil (Frankel et al., 1996). It was suggested that the rosemary antioxidants had greater affinity to the oil-water interface in the fish oil emulsions compared to the vegetable oil emulsions and that this could explain the observed better antioxidative activity of the compounds in the fish oil emulsions. A similar antioxidative effect of rosemary extracts in fish oil-in-water emulsions was observed by Medina et al. (2003), who also found an antioxidative effect of a polyphenol extract from extra virgin olive oil. Faraji and Lindsay (2004) found an antioxidative effect of fructose, sucrose, raffinose, sorbitol, or mannitol when incorporated at levels of $16 \%$ of the aqueous phase into model fish oil-in-water emulsions. Viscosity was changed due to the incorporation of polyols, and viscosity data did not exclude possible contributions from a restricted oxygen diffusion mechanism in the antioxidant activity, but revealed that emulsion viscosity did not govern fish oil oxidation rates.

Rosemary and green tea extracts have been evaluated in other types of fish oil enriched foods than those considered in this review. Thus, an antioxidative effect of the two extracts was found immediately after cooking of n-3 PUFA enriched surimi gels, but during storage the plant extracts exerted a slight pro-oxidant effect (Perez-Mateos et al. 2006). In contrast, a rosemary extract was shown to exert an antioxidative effect when used in combination with citrate and erythorbate in n-3 PUFA enriched ground turkey patties or fresh pork sausages (Lee et al. 2006). 


\section{Effect of other precautions - rapeseed oil addition and oil quality}

Apart from antioxidant addition, other precautions to reduce oxidation in n-3 PUFA enriched food emulsions have been investigated. For milk it has been shown that addition of rapeseed oil to fish oil $(1: 1)$ before the incorporation of the fish oil into the milk is a most efficient way of reducing oxidation. Hence, it was observed that rapeseed oil addition reduced fishy flavour up to $87 \%$ in such n-3 enriched milk. This reduction was higher than that exerted by addition of AP, tocopherol or EDTA (Table 3, 5 and 6). The good antioxidative effect of rapeseed oil has mainly been ascribed to its high level of $\gamma$-tocopherol but it is likely that rapeseed oil also contain other minor compounds that contribute to its protective effect. Other plant oils may have the same antioxidative effect, but have not yet been investigated in milk.

Moreover, the effect of the oil quality on the oxidative stability of milk has been investigated. The findings indicate that the oil quality is even more important than the degree of unsaturation of the fatty acids and it is therefore recommended to use fish oil with a PV lower than $0.5 \mathrm{meq} / \mathrm{kg}$, preferably $\leq 0.1 \mathrm{meq} / \mathrm{kg}$, if the oil is to be incorporated into food emulsion systems. Other precautions such as optimising the processing conditions will also have an effect on the oxidative stability of n-3 enriched food emulsions as also previously demonstrated (Let et al. 2007b; Sørensen et al. 2007; . Finally, other strategies that can protect n-3 fatty acids against oxidation may also be considered. Such strategies could include the use of different delivery systems for n-3 lipids, e.g. microencapsulated lipids or specifically designed $\mathrm{O} / \mathrm{W}$ emulsions engineered to provide optimal protection of the n-3 lipids via the use of interfacial engineering; .

\section{Conclusions and recommendations}

The available data on antioxidative protection of n-3 PUFA in different food emulsions clearly show that the same antioxidant exerts different effects in different systems. The differences in efficacy are partly a result of the dominance of different oxidation mechanisms in different systems, but other factors such as the wide differences in the level of tocopherols as well as other antioxidative compounds originally present in the oils could also explain the different efficacies of 
the added antioxidants. Furthermore, the same antioxidant may in some cases exert different effects on PV, individual volatiles and fishy odour and flavour. Hence, important conclusions are that: a) knowledge of the prevailing mechanism of oxidation in an emulsion is a prerequisite for successful selection of the proper antioxidants, $b$ ) it is necessary to measure several parameters to be able to evaluate antioxidant efficacy. Furthermore, the large differences observed in the antioxidant efficacy of tocopherols in model emulsions with artificial emulsifiers, eg. Brij, versus the (lacking) effects of tocopherols in more genuine emulsion systems using complex natural food emulsifiers such as egg yolk and whey proteins once again highlight the importance of examining antioxidant efficacy in real food systems. On the basis of the data in Table 3-7, the following conclusions and recommendations can be made for the different food systems:

Mayonnaise, salad dressing and milk drink with $5 \%$ fat: EDTA is by far the most efficient antioxidant in mayonnaise, salad dressing and in strawberry flavoured milk drink exerting up to 94 $\%$ reduction in fishy flavour formation in both mayonnaise and milk drink. Therefore, EDTA is recommended as an antioxidant in these food emulsions. Recent data has shown that the antioxidative efficacy of EDTA in fish oil enriched salad dressing can be further improved by the simultaneous addition of $\gamma$-tocopherol and ascorbyl palmitate (Let, Jacobsen \& Meyer, 2007a). Similar effects may be expected in mayonnaise.

Milk with $1.5 \%$ fat: AP is the most efficient antioxidant in milk with $1.5 \%$ fat with up to $73 \%$ reduction in fishy flavour formation, but mixing the fish oil with rapeseed oil before incorporation into milk gives even better protection ( $87 \%$ reduction in fishy flavour formation). It is therefore recommended to use a mixture of rapeseed oil and fish oil for milk. Whether addition of AP to milk made with a mixture of rapeseed oil and fish oil will further improve oxidative flavour stability remains to be investigated. Addition of $\gamma$-tocopherol also provide protection and could be chosen as an alternative solution to AP or rapeseed oil addition.

Model emulsions: The efficacy of the different antioxidants depends on the exact composition of the model emulsions. Thus, strong antioxidative effects have been observed for both EDTA and 
tocopherol in different model emulsions. The emulsifier type and $\mathrm{pH}$ seem to play a major role with respect to which antioxidant is the most efficient in a particular system, suggesting that interactions between emulsifiers and antioxidants may be important. A better understanding of these issues is clearly warranted.

Interestingly, commercially important antioxidants such as propyl gallate and mixtures of tocopherol, and in many cases ascorbic acid, are not efficient in inhibiting oxidation of fish oil enriched food emulsions and should therefore be avoided. In certain cases, eg. in milk, single tocopherol homologues, notably $\gamma$-tocopherol can provide some protection. A final recommendation is also to use fish oil of high quality $(\mathrm{PV}<0.5 \mathrm{meq} / \mathrm{kg})$, especially in milk.

\section{Outlook}

Antioxidant efficacy to retard oxidation varies in different types of n-3 PUFA enriched emulsion systems. Until now, selection of the most efficient antioxidants, and determination of other workable principles to retard oxidation in different n-3 PUFA enriched food emulsion systems have been encircled by systematic experimental work. Detailed mathematical descriptions, unravelling the relative magnitude, and kinetic rates of the different events occurring, are clearly lacking. Notably there is a scarcity of knowledge on the movement and redox changes of transition metal ions in heterophasic systems such as food emulsions. In addition, an estimate of the rates of lipid peroxide diffusion and antioxidant reactivities in different phases of emulsions is missing. Provision of a better quantitative understanding of oxidation events and notably of antioxidant reactions in heterophasic food emulsions would allow a much better prediction of effects of antioxidants in foods. This knowledge is indispensable for fast, rational design and successful development of functional food products containing non-oxidized n-3 PUFA that are efficiently protected against oxidation. 
Table 1. Quantification of antioxidant effects in n-3 PUFA enriched emulsions.

\begin{tabular}{cc}
\hline Antioxidant effect & $\%$ inhibition \\
\hline Prooxidative & $<-5 \%$ \\
No effect & $-5 \%-5 \%$ \\
Weak effect & $5-20 \%$ \\
Intermediate effect & $20-50 \%$ \\
Strong effect & $>50 \%$ \\
\hline
\end{tabular}


Table 2. Composition and storage details about emulsions included in the comparison

\begin{tabular}{|c|c|c|c|c|c|c|c|c|c|}
\hline Product & $\begin{array}{l}\text { Emulsifier } \\
\text { (weight \%) }\end{array}$ & Other additions & Oil type & EPA (\%) & $\begin{array}{l}\text { I data } \\
\text { DHA (\%) }\end{array}$ & $\mathrm{PV}(\mathrm{meq} / \mathrm{kg})$ & $\begin{array}{l}\text { Storage } \\
\text { temperature } \\
{ }^{\circ} \mathrm{C}\end{array}$ & $\begin{array}{l}\text { Storage time } \\
\text { (days/weeks) }\end{array}$ & Ref no \\
\hline Mayonnaise & Egg yolk (4 \%) & See note below & Sand eel oil & $7.9-8.4$ & $7.7-8.4$ & $<0.3$ & 5 & $13-14 \mathrm{w}$ & $A, B, C$ \\
\hline Mayonnaise & Egg yolk (4 \%) & See note below & Sand eel oil & 7.9 & 7.8 & $<0.3$ & 20 & $4 w$ & $G$ \\
\hline Mayonnaise & Egg yolk (4 \%) & See note below & Sand eel oil & nd & nd & 0.9 & 20 & $1 \mathrm{~d}$ & $\mathrm{H}$ \\
\hline Mayonnaise & Egg yolk (4 \%) & See note below & Sand eel oil & nd & nd & $<0.3$ & 20 & $4 w$ & 1 \\
\hline Salad dressing & Whey protein $(0.08 \%)$ & See note below & Cod liver oil & 8.0 & 11.5 & 0.1 & 20 & $6 w$ & $\mathrm{~J}$ \\
\hline \multirow{2}{*}{ Milk $1.5 \%$ fat } & \multirow{2}{*}{ None } & \multirow{2}{*}{ None } & Cod liver oil & 8.3 & 11.8 & 1.48 & \multirow{2}{*}{2} & \multirow{2}{*}{$14 \mathrm{~d}$} & \multirow{2}{*}{ K } \\
\hline & & & Tuna oil & 13.0 & 17.2 & 0.04 & & & \\
\hline Milk $1.5 \%$ fat & None & None & Cod liver oil & 9.7 & 13.4 & 0.19 & 2 & $12 \mathrm{~d}$ & $\mathrm{~L}$ \\
\hline Milk drink $5 \%$ fat & Recodan $(0.2 \%)$ & See note below & SSO & 0.0 & 0.0 & $\mathrm{nd}$ & 2 & $9-11 w$ & $\mathrm{D}, \mathrm{M}$ \\
\hline Milk drink $5 \%$ fat & Recodan $(0.2 \%)$ & See note below & SFO & 14.1 & 11.5 & 2.63 & 2 & $10 w$ & $\mathrm{~N}$ \\
\hline Milk drink $5 \%$ fat & Recodan $(0.2 \%)$ & See note below & RFO & nd & nd & nd & 5 & $2 w$ & 0 \\
\hline Milk drink $5 \%$ fat & Recodan $(0.2 \%)$ & See note below & SFO & nd & nd & nd & 5 & $2 w$ & $\mathrm{P}$ \\
\hline O/W emulsion & Lecithin (1 \%) & $\begin{array}{l}\text { Phosphate-citrate buffer } \\
(25 \mathrm{mM}), \text { pH } 6.6\end{array}$ & $\begin{array}{l}\text { Fish oil and } \\
\text { algal oil }\end{array}$ & $\begin{array}{l}\text { fish: } 5.5 \\
\text { algal: } 0\end{array}$ & $\begin{array}{r}\text { fish: } 27.7 \\
\text { algal: } 50.8\end{array}$ & nd & 40 & $3 d$ & $Q$ \\
\hline $\mathrm{O} / \mathrm{W}$ emulsion & $\begin{array}{l}\text { Whey protein } \\
(2.5 \%)\end{array}$ & $\begin{array}{l}\text { Sodium acetate-imidazole } \\
\text { buffer, } \mathrm{pH} 3 \\
\text { Heated for } 30 \text { min at } 75^{\circ} \mathrm{C} \\
\text { before storage }\end{array}$ & Algal oil & nd & nd & nd & 37 & $8 w$ & $\mathrm{R}$ \\
\hline $\mathrm{O} / \mathrm{W}$ emulsion & $\begin{array}{l}\text { Polyoxyethylene } 100 \\
\text { stearyl ether } \\
\text { (Brij 700) (1\%) }\end{array}$ & $\begin{array}{l}\text { Sodium acetate-imdazole } \\
\text { buffer, } \mathrm{pH} 7.0\end{array}$ & Menhaden oil & nd & nd & nd & 37 & $\begin{array}{c}8 \mathrm{~d}(25 \mu \mathrm{m} \\
\text { tocopherol) } \\
20 \mathrm{~d}(140 \mu \mathrm{m} \\
\text { tocopherol }) \\
\end{array}$ & $S$ \\
\hline $\mathrm{O} / \mathrm{W}$ emulsion & $\begin{array}{l}\text { Lecithin (1 \%), } \\
\text { Chitosan }(0.2 \%)\end{array}$ & $\begin{array}{l}\text { Sodium acetate-imdazole } \\
\text { buffer, pH } 3.0\end{array}$ & Tuna oil & 16.0 & 14.1 & $0.35 \mathrm{mmol} / \mathrm{kg}$ & 37 & $14 \mathrm{~d}$ & $\mathrm{~T}$ \\
\hline
\end{tabular}

Mecodan: Emulsifier and stabiliser consisting of mono- and digclycerides of fatty acids, carageenan and guar gum. Mayonnaise additions: Rapeseed oil (64 \%), $\mathrm{NaCl}(0.3 \%)$, sugar $(1 \%)$, vinegar (4\%), lemon juice $(1.2 \%)$, potassium sorbate $(0.1 \%)$,
stabiliser consisting of guar gum and sodium alginate

Milk drink additions: Strawberry flavour ( $0.13 \%$ ), sugar $(5 \%)$, rapeseed oil (adjust up to $5 \%$ fat), skim milk (adjust up to $100 \%$ )

Salad dressing additions: Rapeseed oil (15\%), vinegar (6\%), Grindsted FF2110 (1.2\%), potassium sorbate ( $0.1 \%$ ), water (adjust up to $100 \%$ ). Grindsted FF 2110 : stabiliser consisting of guar gum and

xanthan gum. SSO: Specific structured sunflower oil, SFO: Specific structured fish oil, RFO: Randomised fish oil. References: A: , B: Jacobsen, Hartvigsen, Lund, Adler-Nissen, Holmer, \& Meyer, 2000a, C:

Not published data, D: , E: , F: , G: , H: , I: , J: , K: , L: , M: , N: , O: Not published data, P: Not published data, Q: , R: , S: , T: 
Table 3. Ability of EDTA to inhibit oxidation in different n-3 PUFA enriched food and model emulsions

\begin{tabular}{|c|c|c|c|c|c|c|c|c|c|c|c|c|}
\hline \multirow[t]{2}{*}{ Product } & \multicolumn{2}{|c|}{$\begin{array}{l}\text { Tocopherol concentration } \\
\text { naturally present in fish oil }\end{array}$} & \multicolumn{2}{|c|}{$\begin{array}{l}\text { EDTA concentration in } \\
\text { product }\end{array}$} & \multicolumn{5}{|c|}{$\begin{array}{l}\text { Effect of EDTA on chemical parameters } \\
\qquad \max \% \text { inhibition }\end{array}$} & \multicolumn{2}{|c|}{$\begin{array}{c}\text { Effect of EDTA on sensory } \\
\text { properties } \\
\% \text { reduction in }\end{array}$} & \multirow[t]{2}{*}{ Ref no } \\
\hline & Type & Concentration $(\mathrm{mg} / \mathrm{kg})$ & $\mathrm{mg} / \mathrm{kg}$ & Molar $(\mu \mathrm{M})$ & PV & $\begin{array}{c}2,4-t, t- \\
\text { heptadienal } \\
\end{array}$ & hexanal & propanal & TBARS & $\begin{array}{l}\text { Fishy } \\
\text { odour }\end{array}$ & Fishy flavour & \\
\hline \multirow{2}{*}{$\begin{array}{l}\text { Mayonnaise } 80 \% \text { fat } \\
16 \% \text { FO }\end{array}$} & \multirow{2}{*}{ Total toc } & \multirow{2}{*}{304} & 6 & 16 & 87 & 77 & nd & nd & nd & nd & nd & \multirow{2}{*}{$\mathrm{D}$} \\
\hline & & & 24 & 63 & 93 & 73 & nd & nd & nd & nd & nd & \\
\hline $\begin{array}{l}\text { Mayonnaise } 80 \% \text { fat } \\
16 \% \text { FO }\end{array}$ & & nd & 200 & 536 & 76 & 99 & 48 & nd & nd & 94 & 94 & G \\
\hline \multirow{2}{*}{$\begin{array}{l}\text { Salad dressing } 25 \% \text { fat } \\
10 \% \text { FO }\end{array}$} & \multirow{2}{*}{ a-toc } & \multirow[b]{2}{*}{200} & 10 & 27 & 84 & 77 & 47 & nd & nd & nd & nd & \multirow{2}{*}{$J$} \\
\hline & & & 50 & 134 & 80 & 78 & 39 & nd & nd & nd & nd & \\
\hline Milk $1.5 \%$ fat & \multirow{3}{*}{ a-toc } & \multirow{3}{*}{260} & 5 & 13 & 5 & 83 & 67 & nd & nd & nd & nd & \multirow{3}{*}{$\mathrm{K}$} \\
\hline $1.5 \% \mathrm{FO}$ & & & 10 & 27 & 8 & 81 & 67 & nd & nd & nd & nd & \\
\hline (cod liver oil) & & & 50 & 134 & 18 & 85 & 48 & nd & nd & 52 & 36 & \\
\hline Milk $1.5 \%$ fat & \multirow{3}{*}{ a-toc } & \multirow{3}{*}{86} & 5 & 13 & -17 & 0 & 0 & nd & nd & nd & nd & \multirow{3}{*}{$\mathrm{K}$} \\
\hline $1.5 \% \mathrm{FO}$ & & & 10 & 27 & 7 & 0 & 0 & nd & nd & nd & nd & \\
\hline (tuna oil) & & & 50 & 134 & 6 & 0 & 0 & nd & nd & 0 & 0 & \\
\hline $\begin{array}{l}\text { Milk } 1.5 \% \text { fat } \\
0.5 \% \text { FO }\end{array}$ & a-toc & 330 & 5 & 13 & 10 & 7 & 2 & nd & nd & 18 & 0 & L \\
\hline $\begin{array}{l}\text { Milk drink } 5 \% \text { fat } \\
5 \% \text { SSO }\end{array}$ & $\alpha, \beta, \gamma$-toc & $57,6.7,1$ & 240 & 643 & 58 & nd & 93 & nd & nd & 78 & 100 & M \\
\hline $\begin{array}{l}\text { Milk drink } 5 \% \text { fat } \\
0.5 \% \text { SFO }\end{array}$ & a-toc, y-toc & $4.5,4.1$ & 240 & 643 & 50 & nd & -56 & nd & nd & 91 & 94 & $\mathrm{~N}$ \\
\hline $\begin{array}{l}\mathrm{O} / \mathrm{W} \text { emulsion } 25 \% \mathrm{FO} \\
2.5 \% \text { whey protein, } \mathrm{pH} 3\end{array}$ & & nd & 37 & 100 & 89 & nd & nd & 95 & nd & nd & nd & $\mathrm{R}$ \\
\hline $\begin{array}{l}\text { O/W emulsion } 5 \% \text { FO } \\
1 \% \text { lecithin, pH } 6.6 \text {, }\end{array}$ & $\alpha, \beta+\gamma$-toc & 451,0 & 37 & 100 & 100 & nd & nd & nd & nd & nd & nd & $Q$ \\
\hline $\begin{array}{l}\text { O/W emulsion } 5 \% \text { FO } \\
1 \% \text { lecithin, pH } 6.6\end{array}$ & $\alpha, \beta+\gamma$-toc & 1729, 208 & 37 & 100 & 100 & nd & nd & nd & nd & nd & nd & $\mathrm{Q}$ \\
\hline \multirow{3}{*}{$\begin{array}{l}\text { O/W emulsion } 5 \% \text { FO } \\
1 \% \text { lecithin, } 0.2 \% \text { chitosan }\end{array}$} & \multirow{3}{*}{\multicolumn{2}{|c|}{ Not detectable }} & 4 & 12 & 36 & $\mathrm{nd}$ & $\mathrm{nd}$ & nd & 43 & $\mathrm{nd}$ & nd & \multirow{3}{*}{$\mathrm{T}$} \\
\hline & & & 22 & 60 & 64 & nd & nd & nd & 57 & nd & nd & \\
\hline & & & 45 & 120 & 64 & nd & nd & nd & 63 & nd & nd & \\
\hline
\end{tabular}

SSO enzyme modified sunflower oil (= structured sunflower oil), SFO enzyme modified fish oil (= structured fish oil), $F O$ fish oil, $n d$ not determined

Fat and fish oil concentrations are stated in $\%$ of total product weight. For identification of references, refer to Table 1. 
Table 4. Ability of lactoferrin to inhibit oxidation in different n-3 PUFA enriched food emulsions

\begin{tabular}{|c|c|c|c|c|c|c|c|c|c|c|}
\hline \multirow[t]{2}{*}{ Product } & \multicolumn{2}{|c|}{$\begin{array}{l}\text { Tocopherol concentration } \\
\text { naturally present in fish oil }\end{array}$} & \multicolumn{2}{|c|}{$\begin{array}{l}\text { Lactoferrin } \\
\text { added in product }\end{array}$} & \multicolumn{3}{|c|}{$\begin{array}{l}\text { Effect of lactoferrin on chemical parameters } \\
\qquad \text { Max \% inhibition }\end{array}$} & \multicolumn{2}{|c|}{$\begin{array}{c}\text { Effect of lactoferrin on sensory } \\
\text { properties } \\
\% \text { reduction in }\end{array}$} & \multirow[t]{2}{*}{ Ref no } \\
\hline & Type & Concentration $(\mathrm{mg} / \mathrm{kg})$ & $\mathrm{mg} / \mathrm{kg}$ & Molar $(\mu \mathrm{M})$ & PV & heptadienal & hexanal & Fishy odour & Fishy flavour & \\
\hline \multirow{4}{*}{$\begin{array}{l}\text { Mayonnaise } 80 \% \text { fat } \\
16 \% \text { FO }\end{array}$} & \multirow{4}{*}{ Total toc } & \multirow{4}{*}{304} & 707 & 7.9 & 60 & 4 & nd & nd & nd & \multirow{8}{*}{$\mathrm{D}$} \\
\hline & & & 1413 & 15.7 & 34 & 14 & nd & nd & nd & \\
\hline & & & 2120 & 23.6 & 32 & -15 & nd & nd & nd & \\
\hline & & & 2826 & 31.4 & 37 & 9 & nd & nd & nd & \\
\hline \multirow{4}{*}{$\begin{array}{l}\text { Milk drink } 5 \% \text { fat } \\
5 \% \text { SSO }\end{array}$} & \multirow{4}{*}{$\alpha, y$-toc } & \multirow{4}{*}{$2.8,0.1$} & 500 & 5.6 & 12 & nd & 1 & nd & nd & \\
\hline & & & 1000 & 11.1 & -14 & nd & 8 & nd & nd & \\
\hline & & & 1500 & 16.7 & 13 & nd & -10 & nd & nd & \\
\hline & & & 2000 & 22.2 & 2 & $\mathrm{nd}$ & -15 & nd & nd & \\
\hline $\begin{array}{l}\text { Milk drink } 5 \% \text { fat } \\
0.5 \% \text { SFO }\end{array}$ & $\alpha, y$-toc & $4.5,4.1$ & 1000 & 22.2 & 43 & nd & -10 & 67 & 81 & $\mathrm{~N}$ \\
\hline
\end{tabular}

SSO enzymatic modified sunflower oil (= structured sunflower oil), $S F O$ enzymatic modified fish oil (= structured fish oil), $F O$ fish oil, $n d$ not determined

Fat and fish oil concentrations are stated in $\%$ of total product weight. For identification of references, refer to Table 1. 
Table 5. Ability of tocopherols to inhibit oxidation in different n-3 PUFA enriched food and model emulsions

\begin{tabular}{|c|c|c|c|c|c|c|c|c|c|c|c|c|c|}
\hline Product & \multicolumn{2}{|c|}{$\begin{array}{l}\text { Tocopherol concentration } \\
\text { Naturally present in fish oil } \\
\text { Type Concentration } \\
\text { Tyg/kg) }\end{array}$} & \multicolumn{2}{|c|}{$\begin{array}{l}\text { Tocopherol concentration } \\
\text { added to product }\end{array}$} & $\begin{array}{l}\text { Total in } \\
\text { product } \\
(\mathrm{mg} / \mathrm{kg})\end{array}$ & \multicolumn{5}{|c|}{$\begin{array}{l}\text { Effect of tocopherol on chemical parameters } \\
\text { Max \% inhibition } \\
\text { 2,4-t,t- }\end{array}$} & \multicolumn{2}{|c|}{$\begin{array}{l}\text { Effect of tocopherol on } \\
\text { sensory properties } \\
\% \text { reduction in }\end{array}$} & Ref no \\
\hline \multirow{4}{*}{$\begin{array}{l}\text { Mayonnaise } 80 \% \text { fat } \\
16 \% \text { FO }\end{array}$} & \multirow{4}{*}{$\begin{array}{l}\alpha \text {-toc } \\
\gamma \text {-toc }\end{array}$} & \multirow{4}{*}{$\begin{array}{l}\text { FO: } 87, \text { RO: } 231 \\
\text { FO: } 10, \text { RO: } 453\end{array}$} & Mix - Oil Sol & 112 & 565 & 26 & -55 & -179 & nd & nd & -44 & -14 & \multirow{4}{*}{ B } \\
\hline & & & Mix - Water Sol & 32 & 485 & 44 & 16 & -2 & nd & nd & 32 & 40 & \\
\hline & & & $\mathrm{A} / \mathrm{L} / \mathrm{T}$ & 17 & 470 & 49 & -78 & -1138 & nd & nd & -94 & -56 & \\
\hline & & & $\mathrm{A} / \mathrm{L} / \mathrm{T}$ & 17 & 470 & 74 & -84 & -622 & nd & nd & -46 & -57 & \\
\hline $\begin{array}{l}\text { Mayonnaise } 80 \% \text { fat } \\
16 \% \text { FO }\end{array}$ & $\begin{array}{l}\alpha \text {-toc } \\
y \text {-toc }\end{array}$ & $\begin{array}{l}\text { FO: } 94, \text { RO: } 251 \\
\text { FO: < } 5 \text {, RO: } 459\end{array}$ & Mix- Water Sol & 32 & 501 & -14 & 78 & 47 & nd & nd & -17 & -23 & E \\
\hline \multirow{7}{*}{$\begin{array}{l}\text { Mayonnaise } 80 \% \text { fat } \\
16 \% \text { FO }\end{array}$} & \multirow{7}{*}{$\begin{array}{l}\text { a-toc } \\
y \text {-toc }\end{array}$} & \multirow{7}{*}{$\begin{array}{l}\text { FO: } 117, \text { RO: } 288 \\
\text { FO: }<5 \text {, RO: } 496\end{array}$} & Mix - Water Sol & 16 & 536 & 57 & 88 & 73 & nd & nd & 34 & 19 & \multirow{7}{*}{$\mathrm{F}$} \\
\hline & & & Mix - Water Sol & 32 & 552 & 8 & 85 & 52 & nd & nd & 22 & 4 & \\
\hline & & & Mix - Water Sol & 56 & 576 & 22 & 65 & 53 & nd & nd & -10 & -7 & \\
\hline & & & Mix - Water Sol & 112 & 632 & 30 & 0 & 30 & nd & nd & 3 & -33 & \\
\hline & & & Mix - Water Sol & 224 & 744 & 24 & -61 & 5 & nd & nd & 32 & -10 & \\
\hline & & & Mix - Oil Sol & 16 & 536 & -8 & 59 & 20 & nd & nd & 22 & 32 & \\
\hline & & & Mix - Oil Sol & 32 & 552 & -41 & 20 & 2 & nd & nd & 25 & 17 & \\
\hline \multirow{2}{*}{$\begin{array}{l}\text { Salad dressing } 25 \% \\
\text { fat } \\
10 \% \text { FO }\end{array}$} & \multirow{2}{*}{$\begin{array}{l}\alpha \text {-toc } \\
y \text {-toc }\end{array}$} & \multirow{2}{*}{$\begin{array}{l}\text { FO: } 200, \mathrm{RO}: 220 \\
\text { FO: } 36, \mathrm{RO}: 365\end{array}$} & vator & 22 & 133 & 36 & 60 & 23 & nd & nd & nd & nd & 1 \\
\hline & & & $Y-\mathrm{IOC}$ & 88 & 199 & 37 & 47 & 14 & nd & nd & nd & nd & $\mathrm{J}$ \\
\hline $\begin{array}{l}\text { Milk } 1.5 \% \text { fat } \\
0.5 \% \text { FO }\end{array}$ & a-toc & 330 & $\begin{array}{c}\alpha \text {-toc }+ \\
y \text {-toc }\end{array}$ & $\begin{array}{c}1.3+ \\
1.8\end{array}$ & * & -62 & -41 & -24 & nd & nd & -21 & -25 & L \\
\hline & & & a-toc & 1.1 & * & 0 & 15 & 7 & nd & nd & nd & nd & \\
\hline Milt 150 & $\alpha$-toc & 330 & $y$-toc & 0.83 & * & 0 & -6 & 6 & nd & nd & nd & nd & 1 \\
\hline $0.5 \%$ FO & & & $y$-toc & 1.65 & * & 0 & 34 & 39 & nd & nd & nd & nd & \\
\hline & & & $y$-toc & 3.3 & * & 0 & 11 & 21 & nd & nd & nd & nd & \\
\hline $\begin{array}{l}\text { O/W emulsion } 5 \% \text { FO } \\
1 \% \text { lecithin, } 0.2 \% \\
\text { chitosan }\end{array}$ & & 0 & Mix & 500 & 500 & -24 & nd & nd & nd & 58 & nd & nd & $\mathrm{T}$ \\
\hline & & & a-toc & 10.8 & * & 82 & nd & nd & 67 & nd & nd & nd & \\
\hline O/W emulsion $5 \%$ FO & & nd & $\delta$-toc & 10.1 & * & 91 & nd & nd & 94 & nd & nd & nd & s \\
\hline 1 \% Brij 700, pH 7 & & na & a-toc & 60.4 & * & 86 & nd & nd & 93 & nd & nd & nd & \\
\hline & & & $\delta$-toc & 60.3 & * & 91 & nd & nd & 96 & nd & nd & nd & \\
\hline
\end{tabular}

FO fish oil, $R O$ rapeseed oil ,Water Sol water soluble tocopherol mixture (G1032), Oil Sol oil soluble tocopherol mixture (Toco 70)

Mix: Tocopherol mixture composition for mayonnaise studies (w/w): $16 \%$ alpha-tocopherol, $58 \%$ beta and gamma-tocopherol and $26 \%$ delta-tocopherol

A/L/T (w/w): $8.6 \%$ ascorbic acid, $86.2 \%$ soybean lecithin, $5.2 \%$ gamma-tocopherol, $n d$ not determined, For identification of references, refer to Table 1.

Fat and fish oil concentrations are stated in $\%$ of total product weight. * Total concentration not known as tocopherol levels are not known in all fat sources. 
Table 6. Ability of ascorbic acid or ascorbyl palmitate to inhibit oxidation in different n-3 PUFA enriched food and model emulsions

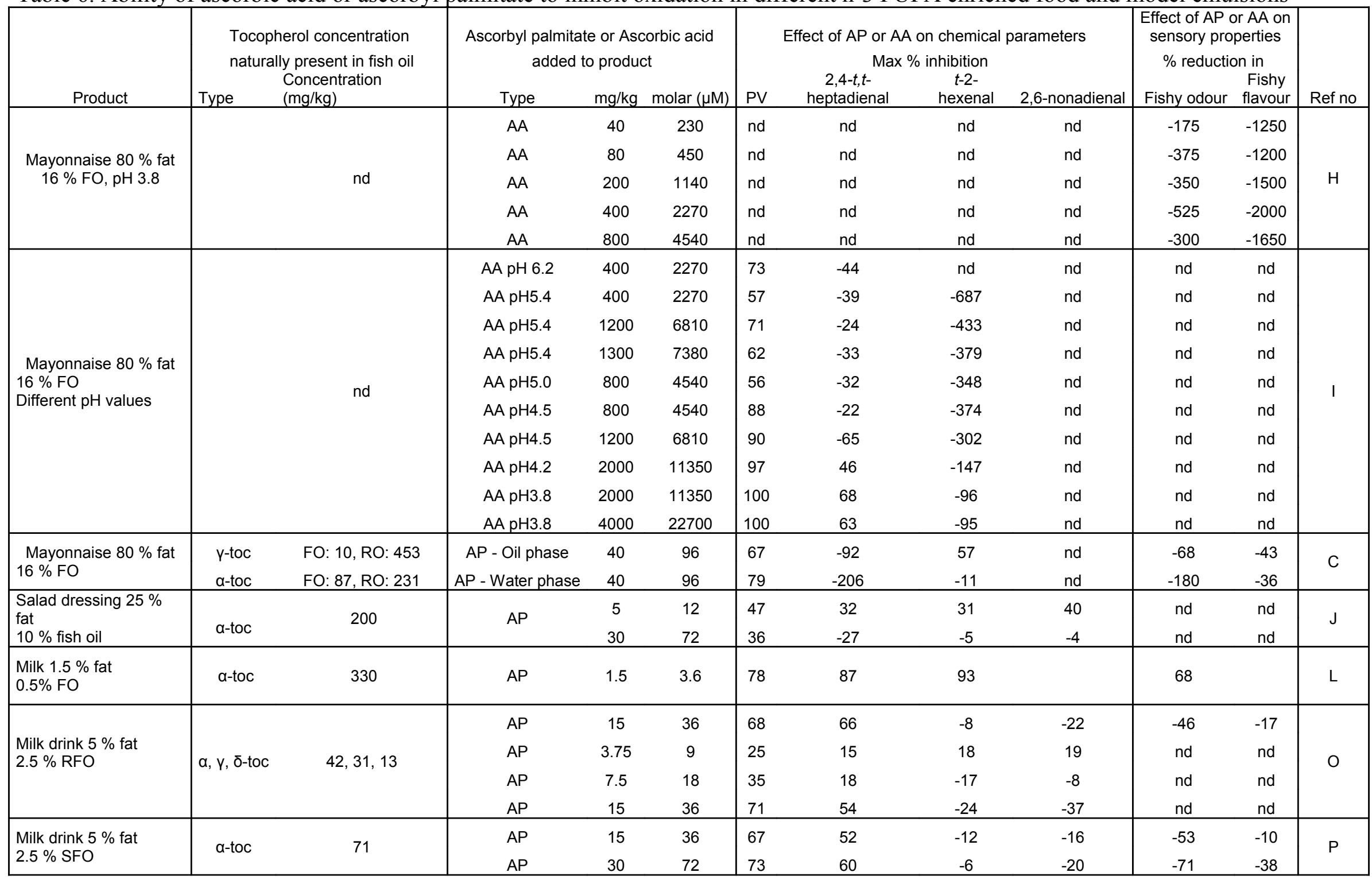


$F O$ fish oil, $R O$ rapeseed oil, $R F O$ chemically modified fish oil (= randomised fish oil), $S F O$ enzyme modified fish oil (=structured fish oil), $A P$ ascorbyl palmitate, $A A$ ascorbic acid, oil phase AP added to oil phase, Water phase AP added to water phase, $n d$ not determined. Fat and fish oil levels are stated in $\%$ of total product weight 
Table 7. Ability of propyl gallate or gallic acid to inhibit oxidation in different n-3 PUFA enriched food emulsions

\begin{tabular}{|c|c|c|c|c|c|c|c|c|c|c|c|c|}
\hline Product & \multicolumn{2}{|c|}{$\begin{array}{l}\text { Tocopherol concentration } \\
\text { naturally present in fish oil } \\
\text { Concentration } \\
\text { Type } \quad(\mathrm{mg} / \mathrm{kg}) \\
\end{array}$} & \multicolumn{3}{|c|}{$\begin{array}{l}\text { Propyl gallate or gallic acid } \\
\text { added to product }\end{array}$} & \multicolumn{4}{|c|}{$\begin{array}{l}\text { Effect of PG or GA on chemical parameters } \\
\text { Max \% inhibition }\end{array}$} & \multicolumn{2}{|c|}{$\begin{array}{l}\text { Effect of } \mathrm{PG} \text { or } \mathrm{GA} \text { on } \\
\text { sensory properties } \\
\% \text { reduction in }\end{array}$} & Ref no \\
\hline Mayonnaise $80 \%$ & a-toc & FO: 88, RO:210 & PG - Oil phase & 40 & 189 & -59 & -71 & 20 & -108 & -104 & 7 & $A$ \\
\hline $16 \%$ FO & $y$-toc & FO: 10, RO: 471 & PG - Water phase & 40 & 189 & -72 & -32 & 16 & -1 & -60 & 2 & $A^{A}$ \\
\hline $\begin{array}{l}\text { Mayonnaise } 80 \% \\
\text { fat } \\
16 \% \text { FO }\end{array}$ & & nd & GA & 200 & 1063 & -7 & 43 & -19 & nd & -25 & -21 & G \\
\hline $\begin{array}{l}\text { Milk drink } 5 \% \text { fat } \\
5 \% \text { SSO }\end{array}$ & $\begin{array}{l}\alpha, \beta, \gamma^{-} \\
\text {toc }\end{array}$ & $57,6.7,1$ & GA & 200 & 1063 & 65 & nd & 47 & nd & See note & See note & M \\
\hline
\end{tabular}

SSO enzyme modified sunflower oil (=structured sunflower oil), $F O$ fish oil, $R O$ rapeseed oil, $P G$ propyl gallate, $G A$ gallic acid, $n d$ not determined.

Note: Milk drink $5 \%$ SSO, the sensory descriptors were rancid odour and flavour instead of fishy odour and flavour. No value for \% inhibition can be given as both pro- and antioxidative effects were seen in a non-systematic pattern. Fat and fish oil concentrations are stated in $\%$ of total product weight.

For identification of references, refer to Table 1. 